\title{
Modal Concord
}

\author{
Hedde Zeijlstra \\ University of Amsterdam
}

\section{Introduction}

Expressions consisting of multiple modal expressions normally yield a cumulative reading. The two modal sentences in (1) and (2) contain two modal elements each (maybe / has and should / allowed, respectively). Semantically, both (1) and (2) contain two modal operators.

\section{(1) Maybe Mary has to leave}

(2) John should be allowed to read this file

However, if two modal elements are of the same modal type (epistemic/ deontic/...) and have similar quantificational force (universal/existential), the most salient reading is mostly not a cumulative one but a concord reading, where the semantics seems to contain only one modal operator. This phenomenon has first been observed by (Halliday 1970) and (Lyons 1977) and has been first analysed by (Geurts and Huitink 2006) who have dubbed it Modal Concord (MC).

(3) You may possibly have read my little monograph upon the subject 'The speaker thinks that it is possible that you read his little monograph'

? 'The speaker thinks that it is possible that it is possible that you read his little monograph'

(4) Power carts must mandatorily be used on cart paths where provided 'It is obligatory that power cats are used on cart paths where provided'

? It is obligatory that it is obligatory that power cats are used on cart paths where provided'

In this paper I attempt to analyse the concord interpretations in (3) and (4). First I argue that the concord readings cannot be the result of an entailment relation and that the phenomenon of Modal Concord is indeed a grammatical phenomenon. In the third section I argue that despite superficial differences Modal Concord behaves strikingly similar to Negative Concord, the phenomenon where two or more morphosyntactically negative element give rise to only one semantic negation. Given this close resemblance, in the fourth section I propose an analysis of Modal Concord that takes it to be the result of a syntactic agreement relation between (one or more) modal auxiliaries. 


\section{Modal Concord is a Grammatical Phenomenon}

An immediate question that rises is whether Modal Concord is a grammatical phenomenon or whether the concord readings can be derived by entailment. In this section I provide three arguments to demonstrate that Modal Concord is indeed a grammatical phenomenon.

The first argument is adopted from (Geurts and Huitink 2006) who have argued that entailment of Modal Concord readings is restricted to the domain of epistemic modality but not deontic modality. The fact that epistemic modality allows for concord readings is due to the fact that the Principles of Veridicality (5) and Positive Introspection (6) apply.

$$
\begin{aligned}
& \text { Veridicality: } \\
& \square \phi \rightarrow \phi \text { (knowledge is factive) }
\end{aligned}
$$

(6) Positive Introspection:

$$
\square \phi \rightarrow \square \square(\equiv \diamond \diamond \phi \rightarrow \diamond \phi)
$$

Thus, the concord reading of (3) is a result of the application of the Principle of Positive Introspection. However, (5) and (6) do not hold for deontic modality. If something is obligatory or desirable, its truth is not guaranteed, and likewise, if something is obligatory, it is not necessarily the case that it is obligatory that it is obligatory. Hence, the instances of deontic Modal Concord demonstrate that Modal Concord readings, at least for deontic modality, cannot be explained by entailment.

A second argument is that Modal Concord can only be established between a modal auxiliary and another modal element as is shown in (7-11). An expression consisting of two non-auxiliary modal elements of the same type cannot yield a Modal Concord reading. This also strongly indicates that Modal Concord is a grammatical phenomenon since the syntactic status of modal auxiliaries appears to be relevant.

(7) The general demands that the troops must leave

$\mathrm{MC}$

(8) John must obligatorily read the books

$\mathrm{MC}$

(9) The general demands that the troops are required to leave

*MC

(10) John mandatorily obligatorily read the books

*MC

(11) Inflectional morphemes are required obligatorily by the syntax *MC

Finally, it can be shown that Modal Concord obeys syntactic locality constraints such as strong islands. The minimal pair in (12) and (13) demonstrates that whereas Modal Concord may be established by a modal verb in the matrix 
clause and a modal auxiliary in the complement clause, Modal Concord cannot be realised if one of the two modal elements is located in an adjunct.

(12) [The general demands that [[when the soldiers surrender] they must behave correctly]] $\rightarrow \mathrm{MC}$

(13) [The general demands that [[when the soldiers must surrender] they behave correctly]] $\rightarrow{ }^{*} \mathrm{MC}$

On the basis of these three arguments I conclude that Modal Concord is a grammatical phenomenon

\section{Modal Concord vs. Negative Concord}

At first sight, Modal Concord appears to behave on a par with other concord phenomena, such as Negative Concord. Negative Concord is the phenomenon where two negative elements give rise to only one semantic negation, as illustrated in (14).

Non ha telefona a nessuno

Italian

Neg has called to n-body

NC: 'He hasn't called anybody'

Since Negative Concord is a grammatical phenomenon as well (see Ladusaw 1996 and Zeijlstra 2004 for an overview of the literature presenting a number of arguments for this claim), the question comes up as to whether Modal Concord is a unique phenomenon or whether it is similar to Negative Concord. And if so, how can Modal Concord and Negative Concord then be explained in a unified way?

With respect to the first question, if Modal Concord is similar to negative Concord, any differences between the two kinds of phenomena need an independent explanation. In this paper I argue that Modal Concord seems to be different in at least three different aspects: (i) Modal Concord is not obligatory whereas Negative Concord usually is; (ii) Modal Concord normally yields an emphatic effect whereas Negative Concord mostly does not do so; and (iii) not any two modal elements may participate in an Modal Concord relation, which seems to be the case with Negative Concord.

\subsection{Modal Concord vs. Negative Concord: Obligatoriness}

Negative Concord constructions are normally obligatory, but Modal Concord constructions are not, as is demonstrated for Italian and Dutch in (15-16) below.

Ieri *(non) ha detto niente Italian Yesterday neg has said $n$-thing 
'Yesterday he didn't say anything'

(16) Alle deelnemers moeten zich (verplicht) registreren

Dutch

All participants must SE (obligatorily) register

'All participants must register themselves'

However, this fact can be captured by taking the positions of the (lower) modal elements into account. In (15) the n-word niente is located VP-in situ. Sentential negation, however, requires negation of the entire VP, which existentially closes off the event variable (Ladusaw 1992, Herburger 2001, Zeijlstra 2004). In (Herburger 2001) it is demonstrated that if an n-word appears in postverbal position without standing in a particular Negative Concord relation, it can only receive a negation that is below the existential quantifier that binds the event variable.

El bébé no está mirando a nada

Spanish

The baby NEG is looking at $n$-thing

(Herburger 2001)

'The baby isn't looking at anything

$\neg \exists \mathrm{x} \exists \mathrm{e}\left[\operatorname{look}^{\prime}(\mathrm{e}) \& \operatorname{Agent}(\mathrm{e}, \mathrm{b}) \&\right.$ thing'(x) \& Patient(e, $\left.\left.\mathrm{x}\right)\right]$

El bébé está mirando a nada

Spanish

The baby is looking at $\mathrm{n}$-thing

(Herburger 2001)

'The baby is staring at nothing'

$\exists \mathrm{e}\left[\operatorname{look}^{\prime}(\mathrm{e}) \& \operatorname{Agent}(\mathrm{e}, \mathbf{b}) \& \neg \exists \mathrm{x}[\right.$ thing'(x) \& Patient $\left.(\mathrm{e}, \mathrm{x})]\right]$

Zeijlstra (2004, 2006), following (Ladusaw 1992), argues that n-words are indefinites that are licensed by either an overt or a covert negative operator. In (17) the n-word nada is licensed by the overt negative operator no, which is outside VP. In (18) no negative marker can be found outside VP, and the n-word is licensed by a VP internal abstract negative operator, which is therefore outscoped by the existential quantifier binding the event variable.

The obligatoriness of $\mathrm{NC}$ in (15) is thus related to the fact that the n-word has been base-generated VP-in situ due to its argumental status and has not moved out of VP. In fact, in languages like Italian if an n-word is moved out of VP, it may not even be overtly licensed by negation, ruling out Negative Concord in those constructions. ${ }^{1}$
Nessuno (*non) ha telefonato
Italian
$\mathrm{N}$-body has called
'Nobody called'

\footnotetext{
${ }^{1}$ Note that this pattern does not apply to all Negative Concord languages. In fact, in most Negative Concord languages the negative markers must be included as well in constructions such as (19). For a discussion of these facts, see (Zeijlstra 2004).
} 
This observation is further supported by the existence of optional NC languages, such as West Flemish and Afrikaans, where the n-word obligatorily scrambles out of VP.

... da Valère niemand (nie) ken

West Flemish

... that Valère n-body (neg) knows

'... that Valère doesn't know anybody'

Due to the scrambling of the n-word, it is already in a position external to VP and the negative marker does not have to be included either.

As Modal Concord does not involve concord relations between a negative marker and one or more arguments but between a modal auxiliary (located in $\mathrm{I}^{\circ}$ $\left(\right.$ or $\left.\mathrm{Mod}^{\circ} / \mathrm{T}^{\circ}\right)$ ) and other modal elements (verbs, adverbs), every modal element is already VP external and therefore high enough to operate by itself. ${ }^{2}$

(21) You may perhaps have read the book

(22) You may have read the book

(23) You have perhaps read the book

In (21-23) all modals take scope from within IP (or ModP/TP). Consequently, no additional concord relation has to be established in order to enable the modal operator to take scope from the appropriate position. This explains the differences between Modal Concord and Negative Concord with respect to obligatoriness.

A similar mechanism applies to the case of deontic Modal Concord in (24) where the sentence without obligatory in (25) can have the same reading as (26) but where the sentence without must cannot receive this reading. Both (24) and (25) indicate that it is obligatory that the students register, but (26) denotes that apparently some registering event is going on and that this event obligatorily has to take place.

(24) The students must obligatorily register

(25) The students must register

(26) The students obligatorily register

This fact is reminiscent of the facts in (17) and (18) where the negative element appeared to be too low in the structure. Comparing the internal distribution of adverbials (cf. Cinque 1999), the position of deontic adverbs is lower than the position of epistemic adverbs and must be in the same clausal domain where most aspectual adverbs take scope. Similar to aspectual modifiers, the modal adverb obligatorily binds the event variable, modifying the event itself rather than that expressing that this event must take place. This is how the reading of (26) can be

\footnotetext{
${ }^{2}$ See (Cinque 1999) for an overview of the position of modal elements in the clausal domain.
} 
explained. Then it follows that if obligatorily is connected with the modal auxiliary must, which is in a higher and VP-external clausal position, (24) receives the same interpretation as (25), modulo the emphatic effects. Note that the way the auxiliary must function in (24) is that of a scope marker, just as the negative marker no in (18).

\subsection{Modal Concord vs. Negative Concord: Emphasis}

The second difference between Modal Concord and Negative Concord concerns the fact that Modal Concord constructions always introduce an emphatic effect whereas Negative Concord constructions generally do not.

However, Negative Concord expressions can also be emphatic. This is for instance the case when particular intonational effects take place but also when Negative Concord is not obligatory, e.g., in Afrikaans or certain dialects of Dutch, as shown in (27-30).

$\mathrm{Sij}$ is nooit beskikbaar nie

Afrikaans

She is n-ever available neg

'She is never available'

(28) Sij is nooit nie beskikbaar nie

Afrikaans

She is n-ever neg available neg

'She is never ever available'

Zij heeft niemand gezien

Dutch

She has n-body seen

'She didn't see anybody'

(30) Zij heeft niemand niet gezien

Subst. Dutch

She has n-body neg seen

'She didn't see anybody at all'

Following (Van der Wouden 1994, Zeijlstra 2004, and Biberauer 2006), those effects can be explained in terms of pragmatics. As the inclusion of the optional negative element does not alter the truth-conditions of the sentence, the inclusion of the redundant element leads to emphatic effect.

The same holds for Modal Concord. As discussed above, Modal Concord is not obligatory (although some modal adverbs require an additional modal auxiliary as a scope marker). Therefore, inclusion of an additional modal element not forced by grammar should lead to an emphatic effect.

\subsection{Modal Concord vs. Negative Concord: Restrictions on Concord}

As has been discussed in Sections 1 and 2, Modal Concord can only apply between a modal auxiliary and another modal element. Modal Concord between, for instance, two modal adverbs is ruled out. 
Apart from that, at least two other restrictions on Modal Concord apply. First of all, the two modal elements have to share the same quantificational force as well as be of the same modal type. This is shown below.

(31) It must necessarily be the case

$\mathrm{MC}$

(32) It may necessarily be the case

*MC

(33) It is allowed that he may enter the room

$\mathrm{MC}$

(34) It is allowed that he might enter the room

$* \mathrm{MC}$

In (31) must and necessarily have the same modal type (epistemic in this case). On top of that they also have the same universal quantificational force. If must were replaced, however, by a modal auxiliary that can be epistemic as well but that exhibits only existential force, like may, Modal Concord cannot be established, as shown in (32).

A similar pattern can be identified in (33-34). In (33) deontic allowed has established a Modal Concord relation with may, which can have a deontic reading as well. However, might is a modal auxiliary that can only be used in epistemic contexts. Allowed and might are therefore not of the same modal type, and although they share the same existential quantificational force, they cannot establish a Modal Concord relation, as is shown in (34).

The question is how these restrictions on Modal Concord are to be compared with the restrictions on Negative Concord. Negative Concord may take place between negative elements of different kinds: negative markers, n-words and negative verbs. In (35) Negative Concord takes place between a negative marker and two n-words, in (36) between a negatively flavoured verb and a negative marker/complimentizer and in (37) between a negatively flavoured verb and an n-word.

Non ha detto niente a nessuno

Italian

Neg has said n-thing to n-body

'He didn't say anything to anybody'

Timeo ne veniat

Latin

Fear neg comes

'I fear that he comes'

Dudo que vayan a encontrar nada

Doubt that will to find $n$-thing

2001)

'I doubt that they will find anything'

Spanish

(Herburger

In most languages all negative elements may establish $\mathrm{NC}$ relations, but exceptions are known. Czech and Russian differ with respect to the 
grammaticality of NC constructions involving bez ('without'), as shown in (38$39)$.

$$
\begin{aligned}
& \text { Bez nikoho } \\
& \text { Without n-body } \\
& \text { 'Without anybody' } \\
& \text { *Bez nikogo } \\
& \text { Without n-body } \\
& \text { 'Without anybody' }
\end{aligned}
$$

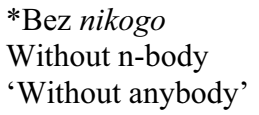

Czech

Russian

In Afrikaans, Negative Concord may take place between an n-word and one or more negative markers, as in (40) but not between two n-words. The sentence in (41) cannot receive a Negative Concord reading.

Sij is nooit nie beskikbaar nie

Afrikaans

She is n-ever neg available neg

'She is never ever available'

(41) Niemand verstaan niks nie

Afrikaans

N-body understand n-thing neg

'Nobody understands nothing'

In Zeijlstra (2004, 2006) these facts are covered by assuming that Negative Concord constructions consist of one element (possibly phonologically abstract) that is semantically negative ([iNEG]) and one or more elements that are semantically non-negative ([uNEG]) and are required to stand in a particular relation with an element that is semantically active (i.e., which carries a feature [iNEG]). Under such a view a Negative Concord relation may only take place between a single element that carries [iNEG] and multiple elements carrying [uNEG]. The fact that Italian allows multiple n-words to establish a relationship with non is then explained by arguing that non carries a feature [iNEG] and the nwords carry a feature [uNEG]. ${ }^{3}$ In Afrikaans, the situation is the reverse. The fact that nie may appear more than once in the clause is due to the fact that the feature carried is [uNEG] and that the n-word is [iNEG]. It then follows that two n-words, both carrying [iNEG] always induce two semantic negations. Under this view, languages may differ cross-linguistically with respect to which kind of negative elements receive semantically interpretable features and which elements receive the uninterpretable ones.

Now this analysis can be transmitted to the realm of modality. Modal elements also come about in different syntactic forms. For instance, one can identify modal verbs (to require, to demand), modal auxiliaries (must, can, may) and modal adverbs (probably, obligatorily). But Modal Concord readings can

\footnotetext{
${ }^{3}$ In all cases where n-words are not licensed by non, Zeijlstra argues that an abstract operator is
} responsible for licensing the [uNEG] features of the n-words. 
only be established between a modal auxiliary and another modal element. Constructions with multiple modal adverbs and/or modal verbs only yield cumulative readings, as shown in (7-11) repeated as (42-46) below.

(42) The general demands that the troops must leave

(43) John must obligatorily read the books

$\mathrm{MC}$

(44) The general demands that the troops are required to leave

$* \mathrm{MC}$

(45) John mandatorily obligatorily reads the books

$* \mathrm{MC}$

Inflectional morphemes are required obligatorily by the syntax

*MC

Multiple modal auxiliaries cannot appear in a single clause in English, but this is due to particular properties of the syntax of English modals. In other languages Modal Concord relations between modal auxiliaries can be established.

*That would can happen

$\begin{array}{ll}\text { Dat zou kunnen gebeuren } & \text { Dutch } \\ \text { That would can happen } & \text { MC } \\ \text { 'That (really) could happen' } & \end{array}$

Apparently, only modal auxiliaries are allowed to introduce a Modal Concord reading. Putting it differently, modal auxiliaries do not always seem to introduce a separate modal operator in the semantics whereas all other types of modal elements do so.

The different behaviour between Negative Concord and Modal Concord could thus also be analysed along the lines of the semantic value of modal features. The data above then indicate that modal adverbs and modal verbs are semantically modal ([iMOD]) whereas modal auxiliaries are not ([uMOD]).

So far, the fact that that only some modal elements may participate in a Modal Concord relation is not a unique property of Modal Concord but can also be found in other domains of concord, such as Negative Concord. However, it has remained an open question thus far how the additional restrictions on Modal Concord should be explained. In this section I discuss the restrictions concerning quantificational force. The restriction concerning the type of modality will be discussed in the next section.

It appears that every instance of Modal Concord is either an instance between two (or more) modal elements sharing universal force or between two (or more) modal elements sharing existential force. Thus, Modal Concord is different from Negative Concord in the sense that Modal Concord is not only an instance of concord with respect to one property (as is the case with Negative Concord) but with respect to two properties. In a way there are (at least) two types of Modal Concord, which could loosely be called Universal Modal Concord and Existential 
Modal Concord. An additional property of modal elements is that every modal element is lexically unambiguous with respect to its quantificational force. An auxiliary like must always has universal quantification force, just as a modal element like can always has existential quantification force. Consequently, the modal quantificational force must be lexically specified.

But if modal elements are already lexically specified for their modal quantificational force, this amounts to saying that every modal element does not have an arbitrary modal feature ([MOD]) but a more specific modal feature that determines its quantificational force. Such a feature is then either of the form [ $\forall-$ MOD] or [ $\exists-M O D]$. But now, the additional restriction on Modal Concord concerning quantificational force follows immediately. If Negative Concord is a relation between different elements carrying a negative feature (either [iNEG] or [uNEG]) and Modal Concord is analysed in a similar way, then Modal Concord can only take place between two (or more) elements that have the same modal feature. Modal Concord would then either be a relation between one modal element that carries a semantically interpretable feature [i $\forall-M O D]$, which can only establish a concord relation with elements carrying [u $\forall-M O D]$, or a relation between an element carrying an interpretable feature [i $\exists-M O D]$, which can only establish a concord relation with elements carrying [u $\exists-\mathrm{MOD}]$.

The question how deeply different modal types must be embedded in the lexical specification of modal elements is discussed in the next section. For now, it suffices to conclude that the fact that Modal Concord is subject to further specification does not imply that the concord mechanism behind it must function in a different way.

\subsection{Concluding Remarks}

The three differences between Modal Concord and Negative Concord that have been mentioned at the beginning of this section can be explained as being the results of the application of independent grammatical principles. Hence, it can be concluded that Modal Concord and Negative Concord are not fundamentally different, thus paving the way for a unified account.

In the next section I argue that the analysis for Negative Concord, provided in (Zeijlstra 2004) also applies to Modal Concord. It should be noted, however, that (Zeijlstra 2004) is not the only analysis for Negative Concord. The only claim to be made in this paper is that this analysis extends to modality as well. It is an open question, however, whether alternative accounts for Negative Concord, such as (Giannakidou 2000, Herburger 2001, De Swart and Sag 2002), can also be applied to account for the Modal Concord effects.

\section{Modal Concord is Syntactic Agreement}

In this section I explore the hypothesis that Modal Concord is an instance of syntactic agreement, as is argued for Negative Concard in (Zeijlstra 2004). Adopting the framework proposed in this theory and applying it to modality, 
every modal element is said to have a particular formal modal feature, which is either semantically active or semantically vacuous. In the latter case, it must be dominated by a modal element that carries a semantically interpretable modal feature. Recall that I have argued that modal auxiliaries carry an interpretable modal feature whereas other modal elements carry an interpretable modal feature.

As discussed above, the quantificational force of modal elements is lexically encoded (in the languages under discussion); therefore, it is natural to assume that modal features are only specified for quantificational force. On the other hand, the modal type is quite often determined by the context of the utterance. Therefore, it is less likely to assume that the featural decomposition of modal elements should exceed the distinction with respect to the modal quantificational force. Hence, the following four modal features are adopted:

$$
\begin{aligned}
& \text { [i } \exists-M O D] \\
& {[\mathrm{u} \exists-\mathrm{MOD}]} \\
& {[\mathrm{i} \forall-\mathrm{MOD}]} \\
& {[\mathrm{u} \forall-\mathrm{MOD}]}
\end{aligned}
$$

Following standard feature checking theory (Chomsky 1995), every element that carries a feature $[\mathrm{u} \forall-\mathrm{MOD}]$ or $[\mathrm{u} \exists-\mathrm{MOD}]$ must have its feature checked against an element carrying [i $\forall-M O D]$ or [i $\exists-M O D]$. However, I adopt the view endorsed in (Zeijlstra 2004) that the only configuration under which this feature checking is allowed in these cases, is the checking relation where the interpretable feature ccommands the uninterpretable feature, a view on agreement that in a similar version has also been proposed by (Adger 2003) among many others. Furthermore, I follow (Hiraiwa 2001, Ura 1996) who have argued that a single interpretable feature may check multiple uninterpretable features. Combining these assumptions, Modal Concord reduces to a configuration of the forms in (50) or (51).

$$
\begin{aligned}
& {\left[\ldots \mathrm{X}_{[\mathrm{i} \exists-\mathrm{MOD}]} \ldots \mathrm{Y}_{[\mathrm{u} \exists-\mathrm{MOD}]} \ldots\left(\mathrm{Z}_{[\mathrm{u} \exists-\mathrm{MOD}]}\right) \ldots\right]} \\
& {\left[\ldots \mathrm{X}_{[\mathrm{i} \forall-\mathrm{MOD}]} \ldots \mathrm{Y}_{[\mathrm{u} \forall-\mathrm{MOD}]} \ldots\left(\mathrm{Z}_{[\mathrm{u} \forall-\mathrm{MOD}]}\right) \ldots\right]}
\end{aligned}
$$

Applying this proposal to the examples that have been discussed so far leads to a proper explanation of the facts. Let us first take into account the two cases of Modal Concord with respect to quantificational force.

You may perhaps have read the book

Sentence (52) contains two modal elements (may and perhaps). May carries a feature [u $\exists-M O D]$, and perhaps carries [i $\exists-M O D]$. This leads to the following syntactic structure:

$$
\text { [CP You may }{ }_{[\mathrm{u} \exists-\mathrm{MOD}]}\left[\text { perhaps }_{[\mathrm{i}-\mathrm{MOD}]}\right. \text { have read the book]] }
$$


However, in this case the licensing order of the modal elements is still reversed. In order to enable proper licensing of the modal elements, the modal element perhaps must be raised at LF to a position dominating IP. Given the fact that modal adverbs are quantificational in nature, such raising is not unexpected at all.

$$
\text { [CP You perhaps }\left[\text { [ï-MOD] i may } \text { [ü-MOD] } \left[\mathrm{t}_{\mathrm{i}}\right.\right. \text { have read the book]] }
$$

Now the modal auxiliary can have its feature checked and both the syntax and semantics of (52) is accounted for.

The same mechanism also applies to the other cases of Modal Concord. The Modal Concord reading of (55) is derived in a similar way as the reading of (52).

(55) The students must obligatorily register themselves

Must carries [u $\forall$-MOD], and obligatorily carries [i $\forall-\mathrm{MOD}]$. Again, obligatorily raises at LF to a position dominating must, and must can have its feature checked, yielding the structure in (56).

(56) $\left[\mathrm{CP}\right.$ The students obligatorily $\mathrm{y}_{[\mathrm{i} \forall-\mathrm{MOD}] \mathrm{i}}$ must $_{[\mathrm{u} \forall-\mathrm{MOD}]}\left[\mathrm{t}_{\mathrm{i}}\right.$ register themselves] $]$

Note that in this case the covert raising of the modal adverb is actually traceable as (55) has a different reading than (57) where raising did not have to take place.

The students obligatorily register themselves

Hence the Modal Concord readings follow from the proposed analysis. A question that immediately arises, though, is what happens if there is only a single modal auxiliary in the sentence. If modal auxiliaries are semantically empty, what is responsible for the modal semantics of (58) and (59)?

(58) John may be at home

John must go home

Again, I argue that these facts are similar to the cases of Negative Concord. In languages like Czech, (Zeijlstra 2004) argues that all overt negative elements carry a feature [uNEG]. In sentences as (60) no overt semantically negative element is present.

(60) Anna není doma

Czech

Anna neg.is at.home

'Anna isn't at home' 
In these cases (Zeijlstra 2004) argues that the negative marker has been licensed by a covert negative operator, in the line of (Ladusaw 1992), and has an underlying structure as in (61).

$$
\text { [Anna Op } \neg[\text { iNEG] není }[\text { uNEG] doma] }
$$

Note that such an abstract operator may only be assumed if there is a negative marker present in the sentence. In other words, an abstract negative operator may only be assumed to be present in a grammatical sentence if there are overt elements in the sentence carrying a feature [uNEG] which could not have been licensed by any other element in the sentence. This could be rephrased in a more general way as in (62).

(62) Only if a particular sentence is grammatical and none of the overt elements is responsible for the grammaticality of the sentence, must the sentence be grammatical due to a covert element.

Now the sentences in (58) and (59) are explained as well. If Negative Concord may involve licensing by abstract negative operators, then Modal Concord may involve licensing by abstract modal operators. Thus if a sentence, in which some modal element carries a feature [u $\forall-M O D]$ or $[\mathrm{u} \exists-M O D]$, is grammatical, it is grammatical due to the presence of a covert modal element carrying [i $\forall-M O D]$ or $[i \exists-M O D]$. This leads to the underlying structures (63) and (64) for (58) and (59), respectively.

(63) John may be home

[John $\mathrm{OP}_{\exists-M O D[i \exists-M O D]}$ must $_{[\exists \forall-M O D]}[\mathrm{vP}$ be home $\left.]\right]$

(64) John must go home

[John $\mathrm{OP}_{\forall-M O D[i \forall-M O D]}$ must $_{[u \forall-M O D]}[$ [vP go home]]

Note that this proposal also excludes cases in which two modal adverbs would receive a Modal Concord reading. As illustrated in (65), modal adverbs always contain an interpretable modal feature, and thus inclusion of two modal adverbs in the same system can only yield a cumulative interpretation.

$$
\text { John mandatorily }{ }_{[i \forall-M O D]} \text { obligatorily } y_{[i \forall-M O D]} \text { read the books }
$$

Likewise, cases where the two modal elements are of different quantificational type cannot receive a Modal Concord interpretation either. In those cases the uninterpretable feature of one type cannot have been checked by the interpretable feature of the other type as is illustrated in (66).

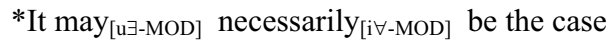


However, a problem results from cases in which no Modal Concord relation has been established because the two modal elements do not match with regard to the modal type. Following the analysis presented above, modal features are not specified for the modal type. Hence, what rules out a concord reading in (67)? Although inevitably is an epistemic modal adverb and must may receive an epistemic reading as well, no Modal Concord reading is available in (67).

$$
\text { Inevitably }_{[i \forall-M O D]} \text { John }_{\text {must }}{ }_{[u \forall-M O D]} \text { leave the room }
$$

*MC

Note that in cases like (67), the Modal Concord reading is unavailable since events selected by must require a deontic reading of must rather than an epistemic one. As is well known, the aspectual status of the VP determines the modal type of the selecting auxiliaries. This is shown in (68) and (69) where the interpretation of must is dependent of the aspectual status of the VP:

(68) John must be at home

(69) John must go home

In (68) the VP denotes a state, and for that reason must is interpreted epistemically. In (69), however, the VP denotes an event, and must must receive a deontic interpretation.

Given the fact that (67) is ungrammatical with a deontic reading due to the aspectual status of its VP, application of (62) allows the inclusion of an abstract modal operator in (67). Hence must has its feature checked by the abstract modal operator, which is interpreted deontically. Thus (67) has the underlying structure as in (70).

(70) [Inevitably $\mathrm{Ii} \forall-\mathrm{MOD}] \mathrm{John} \mathrm{OP}_{\forall-\mathrm{MOD}[\mathrm{i} \forall-\mathrm{MOD}]} \operatorname{must}_{[\mathrm{u} \forall-\mathrm{MOD}]}$ leave the room]

Finally, it follows immediately from the syntactic agreement analysis of Modal Concord that Modal Concord is subject to syntactic locality constraints, such as adjunct islands.

(71) [The general demands that [[when the soldiers surrender] they must behave correctly]] $\rightarrow \mathrm{MC}$

(72) [The general demands that [[when the soldiers must surrender] they behave correctly]] $\rightarrow * \mathrm{MC}$

To sum up, the proposed analysis of Modal Concord in terms of syntactic agreement (implemented in a feature checking system) accounts for the facts that have been presented and, moreover, analyses Modal Concord in a similar way as Negative Concord. 


\section{Conclusions}

In this paper I have argued that Modal Concord is a grammatical phenomenon and that despite superficial differences, it shows close resemblance to the phenomenon of Negative Concord. I have argued that the approach by (Zeijlstra 2004), who takes Negative Concord to be an instance of syntactic agreement, naturally extends to Modal Concord, and I have provided an analysis for Modal Concord by arguing that modal elements carry a modal feature specified for quantificational force, which is either semantically interpretable or uninterpretable. Furthermore, I have proposed that modal auxiliaries are semantically vacuous in languages like English and Dutch and that they only signal the presence of an abstract modal operator of a particular quantificational force.

By analysing Modal Concord in the same way as Negative Concord, all adopted notions, such as abstract operators, have received an independent motivation. Moreover, a unified analysis for two concord phenomena may open the way for a general theory of concord phenomena all based on one and the same syntactic principle.

\section{References}

Adger, David: 2003, Core Syntax: a minimalist approach, Oxford University Press, Oxford/New York.

Chomsky, Noam: 1995, The Minimalist Program, MIT Press, Cambridge, MA.

Cinque, Guglielmo: 1999, Adverbs and Functional Heads - A Cross-Linguistic Perspective, Oxford University Press, Oxford/New York.

Biberauer, Theresa: 2006, "Syntactic” OCP effects? Insights from Afrikaans, Ms. Cambridge University.

De Swart, Henriette and Ivan Sag: 2002, 'Negation and Negative Concord in Romance', Linguistics and Philosophy 25, 373-417.

Geurts, Bart and Janneke Huitink: 2006, 'Modal concord', in P. Dekker and H. Zeijlstra (eds.) Concord Phenomena and the Syntax Semantics Interface, ESSLLI, Malaga.

Giannakidou, Anastasia: 2000, 'Negative ... concord?', Natural Language and Linguistic Theory 18, 457-523.

Halliday, Michael: 1970, 'Functional diversity in language as seen from a consideration of mood and modality in English', Foundations of Language 6, 322-361.

Hiraiwa, Ken: 2001, 'Multiple Agreement and the Defective Intervention Effect', in O. Matsushansky et al. (eds) The Proceedings of the MIT-Harvard Joint Conference (HUMIT 2000), MITWPL, Cambridge, MA.

Herburger, Elena: 2001, 'The Negative Concord Puzzle Revisited', Natural Language Semantics 9, 289-333. 
Ladusaw, William: 1992, 'Expressing negation', in C. Barker and D. Dowty (eds), Proceedings of SALT II, 237-259. Cornell Linguistic Circle, Cornell, NY.

Ladusaw, William: 1996, 'Negation and Polarity Items', in S. Lappin (ed.), The Handbook of Contemporary Semantic Theory, Blackwell, Oxford.

Lyons, John: 1977, Semantics, Cambridge, Cambridge University Press.

Ura, Hiroyuki: 1996, Multiple Feature- Checking: A Theory of Grammatical Function Splitting, Doctoral Dissertation, MIT.

Zeijlstra, Hedde: 2004, Sentential Negation and Negative Concord, Doctoral Dissertation, University of Amsterdam.

Zeijlstra, Hedde: 2007, 'On the syntactic flexibility of formal features', to appear in T. Biberauer, A. Holmberg and I. Roberts (eds.), The Limits of Syntax, Benjamin, Amsterdam. 